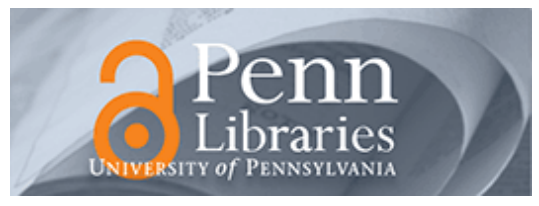

University of Pennsylvania

ScholarlyCommons

2-15-2004

\title{
Signaling by EphrinB1 and Eph Kinases in Platelets Promotes Rap1 Activation, Platelet Adhesion, and Aggregation via Effector Pathways that Do Not Require Phosphorylation of EphrinB1
}

Nicolas Prévost

Donna S. Woulfe

Massimiliano Tognolini

Takako I. Tanaka

University of Pennsylvania, takakot@upenn.edu

Follow this and additional works at: https://repository.upenn.edu/dental_papers

Part of the Dentistry Commons, and the Hematology Commons

\section{Recommended Citation}

Prévost, N., Woulfe, D. S., Tognolini, M., \& Tanaka, T. I. (2004). Signaling by EphrinB1 and Eph Kinases in Platelets Promotes Rap1 Activation, Platelet Adhesion, and Aggregation via Effector Pathways that Do Not Require Phosphorylation of EphrinB1. Blood, 103 (4), 1348-1355. http://dx.doi.org/10.1182/ blood-2003-06-1781 


\title{
Signaling by EphrinB1 and Eph Kinases in Platelets Promotes Rap1 Activation, Platelet Adhesion, and Aggregation via Effector Pathways that Do Not Require Phosphorylation of EphrinB1
}

\begin{abstract}
We have previously shown that platelets express 2 receptor tyrosine kinases, EphA4 and EphB1, and the Eph kinase ligand, ephrinB1m and proposed that transcellular Eph/ephrin interactions made possible by the onset of platelet aggregation promote the further growth and stability of the hemostatic plug. The present study examines how this might occur. The results show that clustering of either ephrinB1 or EphA4 causes platelets to adhere to immobilized firinogen via $\alpha_{l 1 b} \beta_{3}$. Adhesion occurs more slowly than with adenosine diphosphate (ADP) abd requires phosphatidylinositol 3 (PI3)-kinase and protein kinase $C$ activity but not ephrinB1 phosphorylation. By itself, Eph and ephrin signaling is insufficient to cause aggregation or the binding of soluble fibrinogen, but it can potentiate aggregation initiated by a Ca ${ }^{++}$ ionophore or by agonists for thrombin and thromboxane receptors. It also enhances Rap1 activation without requiring ADP secretion, ephrinB1 phosphorylation, or the activation of PI3-kinase and Src. From this we conclude that (1) Eph/ephrin signaling enhances the ability of platelet agonists to cause

aggregation provided that those agonists can increase cytosolic $\mathrm{Ca}^{++} ;(2)$ this is accomplished in part by activating Rap1; and (3) these effects require not phosphotyrosine-based interactions with the ephrinB1 cytoplasmic domain.

Disciplines

Dentistry | Hematology
\end{abstract}

This technical report is available at ScholarlyCommons: https://repository.upenn.edu/dental_papers/48 


\title{
Signaling by ephrinB1 and Eph kinases in platelets promotes Rap1 activation, platelet adhesion, and aggregation via effector pathways that do not require phosphorylation of ephrinB1
}

\author{
Nicolas Prévost, Donna S. Woulfe, Massimiliano Tognolini, Takako Tanaka, Wenying Jian, Ryan R. Fortna, \\ Hong Jiang, and Lawrence F. Brass
}

\begin{abstract}
We have previously shown that platelets express 2 receptor tyrosine kinases, EphA4 and EphB1, and the Eph kinase ligand, ephrinB1, and proposed that transcellular Eph/ephrin interactions made possible by the onset of platelet aggregation promote the further growth and stability of the hemostatic plug. The present study examines how this might occur. The results show that clustering of either ephrinB1 or EphA4 causes platelets to adhere to immobilized fibrinogen via $\alpha_{\| l b} \beta_{3}$. Adhesion occurs more slowly than with
\end{abstract}

adenosine diphosphate (ADP) and requires phosphatidylinositol 3 (PI3)-kinase and protein kinase $C$ activity but not ephrinB1 phosphorylation. By itself, Eph and ephrin signaling is insufficient to cause aggregation or the binding of soluble fibrinogen, but it can potentiate aggregation initiated by a $\mathrm{Ca}^{++}$ionophore or by agonists for thrombin and thromboxane receptors. It also enhances Rap1 activation without requiring ADP secretion, ephrinB1 phosphorylation, or the activation of PI3-kinase and Src. From this we conclude that (1) Eph/ephrin signaling enhances the ability of platelet agonists to cause aggregation provided that those agonists can increase cytosolic $\mathrm{Ca}^{++}$; (2) this is accomplished in part by activating Rap1; and (3) these effects require oligomerization of ephrinB1 but not phosphotyrosine-based interactions with the ephrinB1 cytoplasmic domain. (Blood. 2004;103:1348-1355)

๑) 2004 by The American Society of Hematology

\section{Introduction}

Formation of a platelet plug at sites of vascular injury begins with the arrest of circulating platelets on collagen and continues as additional platelets are recruited by secreted or locally generated agonists such as adenosine diphosphate (ADP), thromboxane $\mathrm{A}_{2}$ $\left(\mathrm{TxA}_{2}\right)$, and thrombin. Once initiated, the ability of the platelet mass to continue to grow depends in part upon the intracellular events that promote the binding of the integrin $\alpha_{\mathrm{IIb}} \beta_{3}$ on the platelet surface to fibrinogen, fibrin, and von Willebrand factor (VWF). In turn, sustained contacts between platelets, which can only occur once aggregation has begun, make possible a wave of contactdependent signaling that favors the further growth and stability of the platelet plug. In this context, the phrase "contact-dependent signaling" refers to the intracellular signaling events initiated by the binding of proteins on the surface of one platelet to proteins on the surface of an adjacent platelet, either directly or indirectly.

Among the examples of contact-dependent signaling that have been described in platelets, outside-in signaling through $\alpha_{\text {II }} \beta_{3}$ is the best known; however, others exist as well. We have recently shown that human platelets express on their surface 2 Eph kinases, EphA4 and EphB1, as well as the Eph kinase ligand, ephrinB1. ${ }^{1}$ Eph kinases are receptor tyrosine kinases with an extracellular ligand-binding domain and an intracellular kinase domain. Eph kinases and their ligands, which are known as ephrins, play a role in axon guidance ${ }^{2}$ and development of the vascular system. ${ }^{3,4}$ Ephrins fall into A and B groups based on their membrane anchor. Ephrin A family members have a glycosylphosphatidylinositol (GPI) anchor.

From the Departments of Medicine and Pharmacology and the Center for Experimental Therapeutics at the University of Pennsylvania, Philadelphia, PA.

Submitted June 3, 2003; accepted October 16, 2003. Prepublished online as Blood First Edition Paper, October 23, 2003; DOI 10.1182/blood-2003-06-1781.

Supported by National Institutes of Health (NIH) grant P01-HL40387.

N.P. and D.S.W. contributed equally to this work.
Ephrin B family members have a transmembrane domain and a cytoplasmic domain. The cytoplasmic domain includes sites for tyrosine phosphorylation and a C-terminal binding site for cytosolic proteins with PDZ domains. This gives the B ephrins at least 2 ways to engage in protein/protein interactions, both of which allow the ligand to serve as a "receptor" even though it does not have a kinase domain. ${ }^{5,6}$ Eph kinases are also divided into $\mathrm{A}$ and $\mathrm{B}$ families based on their ephrin-binding preferences, although EphA4 in particular can bind to ephrin B as well as ephrin A family members. ${ }^{7}$ Thus, human platelets express on their surface at least 2 Eph kinases and a ligand that can bind to either.

Studies in cells that are normally adherent have shown that transcellular interactions between ephrins and Eph kinases can produce signals in both the ephrin- and the Eph kinase-presenting cell and that these signals can result in increased adhesion or repulsion. ${ }^{2,8,9}$ Given the fact that platelets are normally mobile, we have previously proposed that $\mathrm{Eph} / \mathrm{ephrin}$ interactions promote the growth and stability of the platelet plug. ${ }^{10}$ Such interactions would not be expected to occur during the transient contacts between circulating platelets but would be made possible by the onset of aggregation. In support of this hypothesis, we observed that signaling through EphA4 and ephrinB1 causes platelets to adhere to immobilized fibrinogen and triggers the tyrosine phosphorylation of the $\beta 3$ cytoplasmic domain of $\alpha_{\mathrm{IIb}} \beta_{3}$. We also observed that EphA4 forms a complex with Fyn, Lyn, and the cell adhesion molecule L1 during platelet aggregation, and that blockade of

Reprints: Lawrence F. Brass, University of Pennsylvania, Room 913 BRB-II, 421 Curie Blvd, Philadelphia, PA 19104; e-mail: brass@mail.med.upenn.edu.

The publication costs of this article were defrayed in part by page charge payment. Therefore, and solely to indicate this fact, this article is hereby marked "advertisement" in accordance with 18 U.S.C. section 1734.

(C) 2004 by The American Society of Hematology 
Eph/ephrin interactions prevents this association. Finally, we found that blockade of Eph/ephrin interactions during platelet aggregation initiated by ADP, a protease-activated receptor 1 (PAR1) agonist (SFLLRN), or collagen causes premature disaggregation and inhibits clot retraction. ${ }^{1,11,12}$

The goal of the present study was to better understand the ways in which Eph/ephrin signaling can regulate $\alpha_{I I b} \beta_{3}$ activation in platelets and identify mechanisms that might be involved. We now show that Eph/ephrin signaling is able to potentiate platelet aggregation in response to agonists and also promotes the ability of platelet agonists to activate Rap1, a Ras family member that has been linked to integrin activation in a variety of cell types including platelets. We also show that the adhesion of platelets to immobilized fibrinogen in response to $\mathrm{Eph} / \mathrm{ephrin}$ interactions requires phosphatidylinositol 3 (PI3)-kinase and protein kinase $\mathrm{C}$, but, interestingly in light of what is known about signaling by ephrin $\mathrm{B}$ family members, neither the induction of adhesion nor Rap1 activation requires ephrin $\mathrm{B} 1$ phosphorylation or the activation of Src kinases. These results help to establish a model in which contact-dependent Eph/ephrin interactions between adjacent platelets promote platelet aggregation by helping to sustain integrin activation.

\section{Materials and methods}

\section{Chemicals and reagents}

Alexa-Fluor 594-conjugated fibrinogen was from Molecular Probes (Eugene, OR). Wortmannin, LY294002, PP2, PP3, ionomycin, U46619, and bis-indolylmaleimide were from Calbiochem (San Diego, CA). ADP, apyrase, RGDS peptide, phorbol myristate acetate (PMA), and the protease inhibitor cocktail 4-(2-aminoethyl) benzenesulfonyl fluoride, pepstatin A, trans-epoxysuccinyl-L-Leucyl-amido (4-guanidino) butane (E-64), bestatin, leupeptin, and aprotinin were purchased from Sigma (St Louis, MO). Protein A and G agarose were obtained from Gibco BRL (Gaithersburg, $\mathrm{MD})$. Cyanogen bromide (CNBr)-activated Sepharose 4 was from Amersham Pharmacia Biotech (Piscataway, NJ). Convulxin was a gift from Dr Mark Kahn (University of Pennsylvania, Philadelphia, PA).

\section{Platelet preparation}

Blood was obtained from healthy volunteer donors, who had not taken medications for at least 10 days, and was anticoagulated 1:5 with ACD (trisodium citrate $65 \mathrm{mM}$, citric acid $70 \mathrm{mM}$, dextrose $100 \mathrm{mM}, \mathrm{pH} 4.4$ ). Platelet-rich plasma (PRP) was obtained by centrifugation at $100 \mathrm{~g}$ for 20 minutes and then recentrifuged at $220 \mathrm{~g}$ for 15 minutes after adding $1 \mu \mathrm{M}$ prostaglandin $\mathrm{I}_{2}\left(\mathrm{PGI}_{2}\right)$. The platelet pellet was resuspended in $\mathrm{NaCl} 150$ $\mathrm{mM}, \mathrm{Na}_{2}$ EDTA $\left(\mathrm{Na}_{2}\right.$ ethylenediaminetetraacetic acid) $1 \mathrm{mM}$, HEPES ( $N$-2-hydroxyethylpiperazine- $N N^{\prime}$-2-ethanesulfonic acid) $10 \mathrm{mM}, \mathrm{pH} 6.5$, with $1 \mu \mathrm{M} \mathrm{PGI} 2$ and then centrifuged for 15 minutes at $220 \mathrm{~g}$. After washing, the platelets were resuspended in modified Tyrode buffer $(\mathrm{NaCl}$ $137 \mathrm{mM}$, HEPES $20 \mathrm{mM}$, glucose $5.6 \mathrm{mM}$, bovine serum albumin [BSA] $1 \mathrm{~g} / \mathrm{L}, \mathrm{MgCl}_{2} 1 \mathrm{mM}, \mathrm{KCl} 2.7 \mathrm{mM}, \mathrm{NaH}_{2} \mathrm{PO}_{4} 3.3 \mathrm{mM}, \mathrm{pH}$ 7.4) and adjusted to a final platelet count of $1000 \times 10^{9} / \mathrm{L}$. Gel-filtered platelets (GFPs) were prepared by passing the platelet-rich plasma through columns of Sepharose 2B (Pharmacia, Uppsala, Sweden) using modified Tyrode buffer for elution.

\section{Antibodies}

Antibodies for EphA4, ephrinB1, and phosphotyrosine (PY20) were purchased from Santa Cruz (Santa Cruz, CA). The antibody used to precipitate EphA4 was produced in chickens immunized with a peptide corresponding to residues M976-V986 of human EphA4. The antibody used to precipitate ephrinB1 was purchased from R\&D Systems (Minneapolis, MN). Antiphosphotyrosine antibody 4G10 was from Upstate Biotechnology (Lake Placid, NY). The Rap1 antibody was from Transduction Labs (Lexington, KY).

\section{Platelet adhesion}

Platelet adhesion was measured using a modification of the method described by Bellavite et al. ${ }^{13}$ Microtiter plates were coated overnight at $4^{\circ} \mathrm{C}$ with either $2 \mathrm{mg} / \mathrm{mL}$ fibrinogen or $4 \mathrm{mg} / \mathrm{mL}$ BSA in phosphate-buffered saline (PBS) and then blocked with $5 \mathrm{mg} / \mathrm{mL}$ BSA for 15 to 30 minutes. Gel-filtered platelets $\left(50 \mu \mathrm{L}\right.$ of $\left.100 \times 10^{9} / \mathrm{L}\right)$ were added to each well and preincubated at $37^{\circ} \mathrm{C}$ for 5 minutes before the addition of an agonist in 25 $\mu \mathrm{L}$ of Tyrode buffer with $3 \mathrm{mM} \mathrm{CaCl}$. After incubation at room temperature, the plates were washed 4 times in PBS to remove loosely adherent and nonadherent platelets, and acid phosphatase substrate $(150 \mu \mathrm{L}$ of $5 \mathrm{mM} P$-Nitrophenyl phosphate in $0.1 \mathrm{M}$ citrate/0.1\% Triton X-100) was added to each well. This reaction was allowed to proceed for 1 hour at room temperature in the dark and then stopped with $100 \mu \mathrm{L}$ of $2 \mathrm{~N} \mathrm{NaOH}$ per well and optical density (OD) 405 was measured. To determine the fraction of applied platelets that became adherent, an aliquot of platelet suspension containing the same total number of platelets was separately lysed and assayed for acid phosphatase activity. Except for Figure 1A, the results of each experiment were expressed as the "adhesion index" that was defined as the average OD 405 in the presence of an agonist at any given time divided by the average OD 405 in the absence of an agonist at time zero.

\section{Fibrinogen binding}

Platelets ( $300 \mu \mathrm{L}$ of gel-filtered platelets in buffer supplemented with $1 \mathrm{mM}$ $\mathrm{CaCl}_{2}$ ) were incubated with $100 \mu \mathrm{g} / \mathrm{mL}$ Alexa-Fluor 594-labeled fibrinogen for 30 minutes in the dark at room temperature in presence of the appropriate agonist. Platelets were then fixed for 10 minutes at room temperature by adding an equal volume of $2 \%$ formaldehyde-Tyrode buffer, sedimented at $1310 \mathrm{~g}$ for 20 seconds, resuspended in $0.5 \mathrm{~mL}$ phosphate buffered saline, and analyzed by flow cytometry.

\section{Platelet aggregation}

Platelet aggregation was observed in a ChronoLog platelet aggregometer (Havertown, PA) using gel-filtered platelets $\left(200 \times 10^{9} / \mathrm{L}\right)$ supplemented with $1 \mathrm{mM} \mathrm{CaCl}_{2}$ and $300 \mu \mathrm{g} / \mathrm{mL}$ fibrinogen.

\section{Rap1 activation}

Washed platelets $\left(400 \times 10^{9} / \mathrm{L}\right)$ in Tyrode buffer with $1 \mathrm{mM} \mathrm{CaCl}_{2}$ were stimulated with an agonist or inhibitor as indicated, lysed with $2 \times$ buffer
A

Figure 1. Activation of ephrinB1 or EphA4 causes platelet adhesion to fibrinogen. Adhesion was measured using a colorimetric assay as described in "Materials and methods." (A) Platelets were incubated with ADP $(20 \mu \mathrm{M})$ or without an agonist for the times indicated. The figure is representative of 3 experiments. (B-C) Platelets were stimulated with ADP $(20 \mu \mathrm{M})$, GST-EphB1 (5 $\mu \mathrm{g} / \mathrm{mL}$; panel B), or GST-ephrinA4 ( $5 \mu \mathrm{g} / \mathrm{mL}$; panel C) for the times indicated. The results are the mean \pm SEM for 4 experiments expressed as the "adhesion index," which is defined in "Materials and methods."

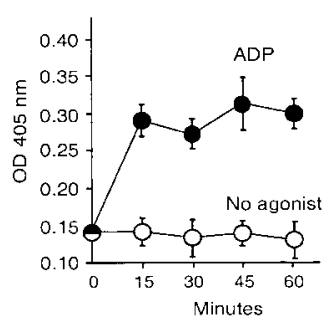

B

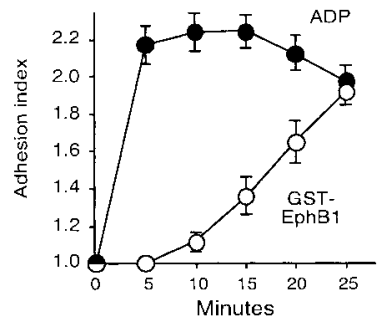

C

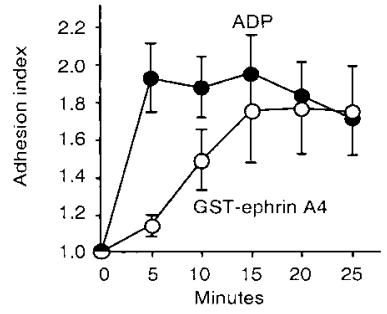


(20\% glycerol, 2\% nonidet P-40 [NP-40], 100 mM Tris-HCl, pH 7.4, 400 $\mathrm{mM} \mathrm{NaCl}, 5 \mathrm{mM} \mathrm{MgCl}$, with mammalian protease inhibitor cocktail), and then incubated for 2 hours with glutathione $S$-transferase (GST)-RalGDSRBD (a fusion of GST with the Ral binding domain [RBD] from the protein RalGDS; $30 \mu \mathrm{g} / \mathrm{mL}$ ) and $50 \mu \mathrm{L}$ glutathione-Sepharose at $4^{\circ} \mathrm{C}$ while rotating. The beads were then washed once with $1 \times$ lysis buffer followed by 3 washes with PBS. Guanosine 5' -triphosphate (GTP)-bound Rap1 was eluted with sodium dodecyl sulfate (SDS) sample buffer, separated by $10 \%$ SDS-polyacrylamide gel electrophoresis (SDS-PAGE), and immunoblotted with anti-Rap1 antibody (1:500).

\section{Immunoprecipitation and Western blotting}

Platelets were either lysed in RIPA buffer (Triton X-100 1\%, deoxycholate $1 \%$, SDS $0.1 \%, 158 \mathrm{mM} \mathrm{NaCl}$, Tris $10 \mathrm{mM} \mathrm{pH} 7.2$, NaEDTA $5 \mathrm{mM}$ ) or in NP-40 buffer (1\% NP-40, $50 \mathrm{mM}$ Tris, $150 \mathrm{mM} \mathrm{NaCl})$, in the presence of protease inhibitors and $\mathrm{NaVO}_{4}(1 \mathrm{mM})$. Insoluble materials were removed by centrifugation at $16000 \mathrm{~g}$ for 15 minutes at $4^{\circ} \mathrm{C}$. The resulting supernatants were precleared with protein $\mathrm{A}$ agarose (for rabbit antibodies), protein $\mathrm{G}$ agarose (for mouse antibodies), or Sepharose 4B beads (for chicken anti-EphA4) and then incubated with the precipitating antibody overnight at $4^{\circ} \mathrm{C}$ with rocking. Protein/antibody complexes were isolated by incubation with either protein A agarose, protein G agarose, or Sepharose 4B for 1 hour at $4{ }^{\circ} \mathrm{C}$ with rocking. After 3 washes in PBS, the beads were boiled in sample buffer ( $2 \%$ SDS, $1 \% \beta$-mercaptoethanol, $0.008 \%$ bromophenol blue [BPB], $80 \mathrm{mM}$ Tris pH 6.8, $1 \mathrm{mM}$ EDTA). The samples were then analyzed by SDS-PAGE and transferred to nitrocellulose membranes. After the transfer, the membranes were blocked in 5\% BSA for a phosphotyrosine blot or in 5\% milk for any other Western blot. When indicated, the membranes were stripped in $62.5 \mathrm{mM}$ Tris- $\mathrm{HCl}, \mathrm{pH}$ 6.8, with $2 \%$ SDS and $100 \mathrm{mM} \beta$-mercaptoethanol for 10 minutes at $63^{\circ} \mathrm{C}$ and then reprobed with a different primary antibody.

\section{Fusion proteins}

The EphA4 exodomain (W54 to V430) was subcloned by polymerase chain reaction (PCR) using a forward primer containing a custom EcoRI site, 5'AATGAATTCAACTGAT TGGTCTGGGTTAGG3', and a reverse primer containing a custom BamHI site, 5'TCCGGATCCTGGGAGGAAGTGAGTATCATGGATG3'. The fragment was subcloned in the pGEX1 $\lambda$ T vector (Amersham Pharmacia BioTech). The resulting construct was transformed into the Escherichia coli strain BL21 DE3. Recombinant GST-EphA4 was purified using the Pharmacia GST purification kit. The presence of oligomers was confirmed by electrophoresis under nondenaturing conditions. Monomeric His6-tagged proteins corresponding to the exodomains of EphB1 and ephrinA4 (HisEphB1 and His-ephrinA4), GST-EphB1, GST-ephrinA4, and GST$\Delta$ EphB1 were prepared as previously described. ${ }^{1}$

\section{Results}

We have previously observed with fluorescence microscopy that activation of EphA4 or ephrinB1 causes platelets to adhere and spread on immobilized fibrinogen. ${ }^{1}$ In the present studies, adhesion was quantitated using a microtiter plate assay. To minimize agonist-independent binding of the platelets, measurements were performed at room temperature and the fibrinogencoated microtiter plate wells were blocked with bovine albumin (BSA). After washing to remove nonattached cells, the adherent platelets were detected using a chromogenic substrate for acid phosphatase. Under these conditions, there was little "background" adhesion in the absence of an agonist at times as long as 60 minutes but a prompt increase in adhesion in response to ADP (Figure 1A). In order to normalize values, results from replicate experiments were combined using a calculated "adhesion index" (defined in "Platelet adhesion"). Approximately half of the applied platelets typically became adherent upon stimulation with ADP. Isolated signaling through ephrinB1 or EphA4 was triggered by incubating the platelets with oligomeric proteins composed of the exodomain of either EphB1 (to activate ephrinB1) or ephrinA4 (to activate EphA4) fused to glutathione-S-transferase (GST).

Consistent with our previous observations, adhesion occurred following the addition of either GST-EphB1 or GSTephrinA4. There was little or no adhesion when fibrinogen was omitted or when the platelets were stimulated with either GST alone or with a variant protein (denoted GST- $\Delta$ EphB1) lacking residues needed for binding to ephrinB $1^{14}$ (Figures $1 \mathrm{~B}-\mathrm{C}$ and 2A-C). His-tagged monomeric exodomains of EphB1 or ephrinA4 were unable to cause adhesion. Preincubating platelets with the monomers prevented a subsequent response to GSTEphB1 or GST-ephrinA4 (Figure 2A-B) but had no effect on adhesion in response to the PAR1 agonist peptide, SFLLRN (not shown). The extent of adhesion in response to clustering EphA4 or ephrinB1 approached that seen with ADP, but the rate was slower (Figure 1B-C). Addition of the integrin-blocking peptide, RGDS, or an anti- $\alpha_{\mathrm{IIb}} \beta_{3}$ antibody (A2A9) prevented adhesion (Figure 2D-F). Taken together, these results show that isolated signaling produced by oligomerization of EphA4 or ephrinB 1 causes a gradual sustained increase in $\alpha_{\text {IIb }} \beta_{3}$-dependent attachment of platelets to immobilized fibrinogen.
A

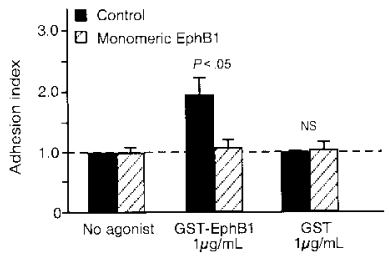

D

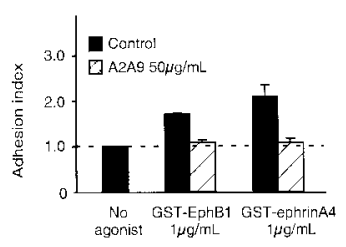

B

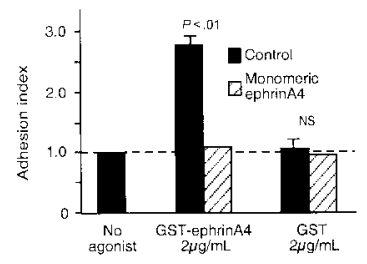

E

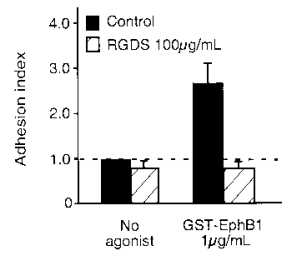

C

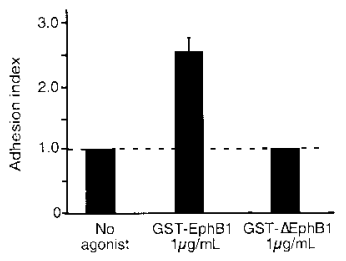

$\mathbf{F}$

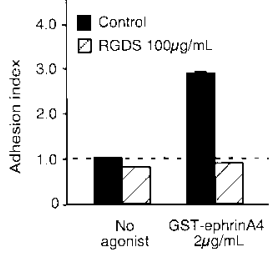

Figure 2. Platelet adhesion to fibrinogen in response to ephrinB1 or EphA4 is mediated by $\alpha_{\| \mathrm{Ib}} \boldsymbol{\beta}_{3}$. (A-B) Platelets were preincubated for 30 minutes with recombinant monomeric proteins corresponding to the exodomain of either (A) EphB1 $(10 \mu \mathrm{g} / \mathrm{mL})$ or (B) eph$\operatorname{rin} A 4(10 \mu \mathrm{g} / \mathrm{mL})$ and then stimulated with GST-EphB1, GST-ephrinA4, or GST for an additional 20 minutes. Mean \pm SEM for 3 experiments. (C) Platelets were incubated with GST-EphB1 or GST- $\Delta$ EphB1 for 20 minutes. Mean \pm SEM for 6 experiments. (D-F) Platelets were preincubated for 30 minutes with the monoclonal anti- $\alpha_{\| b} \beta_{3}, A 2 A 9$, or with RGDS, and then stimulated with GST-EphB1 or GST-ephrinA4 for 20 minutes as indicated. Mean \pm SEM for 3 to 4 experiments. 
Figure 3. Activation of ephrinB1 potentiates platelet aggregation. (A) Gel-filtered platelets $(200 \times 109 / \mathrm{L})$ were incubated with either $2 \mu \mathrm{g} / \mathrm{mL}$ GST-EphB1, GST$\Delta$ EphB1, GST-ephrinA4, or $20 \mu \mathrm{M}$ ADP in presence of $100 \mu \mathrm{g} / \mathrm{mL}$ Alexa-Fluor 594-labeled fibrinogen as described in "Materials and methods." The results shown are representative of 3 experiments. (B-D) Gel-filtered platelets $\left(200 \times 10^{9} / \mathrm{L}\right.$ to $\left.400 \times 10^{9} / \mathrm{L}\right)$ were stimulated as indicated with U46619, SFFLRN, or ionomycin in the presence of GST-EphB1, GST- $\Delta$ EphB1, or buffer, in the order shown. Representative of 4 experiments.

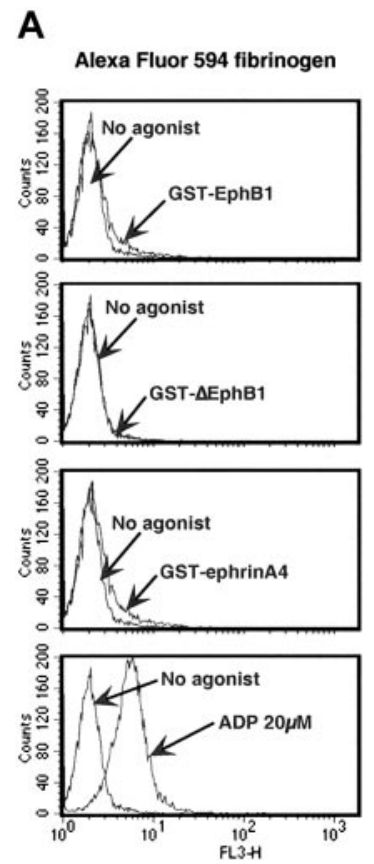

B

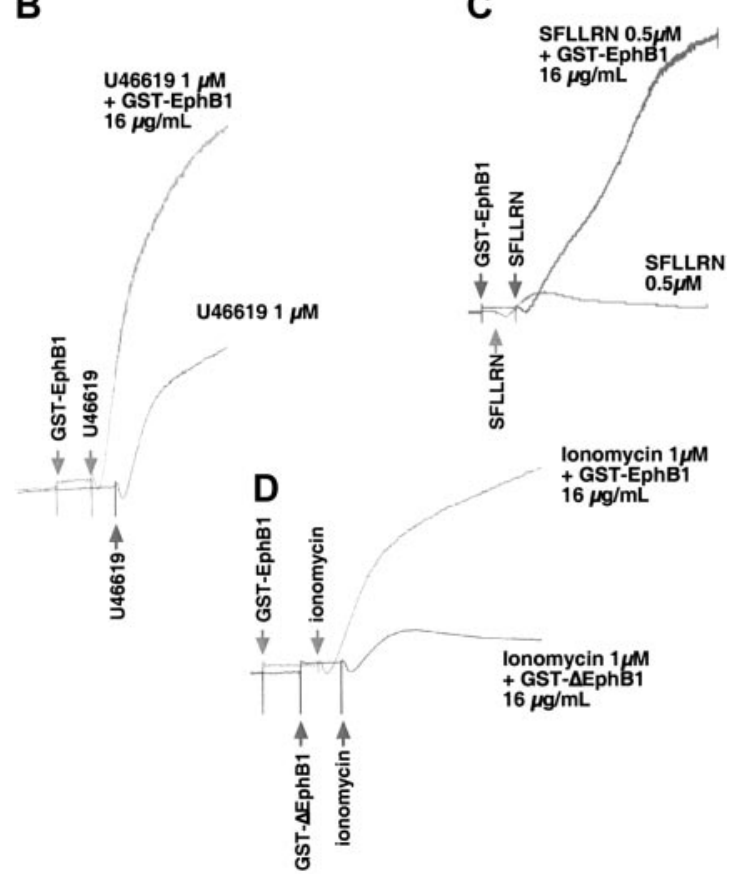

\section{EphrinB1 signaling potentiates platelet aggregation}

We next asked whether signaling through ephrinB1 or EphA4 is able to evoke the high-affinity state of $\alpha_{\text {IIb }} \beta_{3}$ needed for soluble fibrinogen to bind and platelet aggregation to occur. In the experiment shown in Figure 3A, platelets were incubated with GST-EphB1, GST-ephrinA4, or ADP, and labeled fibrinogen binding was measured by flow cytometry. Under these conditions ADP caused fibrinogen binding but the GST fusion proteins did not. When added by itself, GST-EphB1 also failed to cause platelet aggregation (Figure 3 and data not shown). However, incubation with GST-EphB1 increased the rate and extent of aggregation initiated by SFLLRN or the TxA 2 analog, U46619 (Figure 3B-C). GST-EphB1 also increased the ability of the $\mathrm{Ca}^{++}$ionophore, ionomycin, to cause aggregation (Figure 3D). It did not increase platelet responses to epinephrine (not shown).

Therefore, although ephrinB1 signaling alone is unable to cause the binding of soluble fibrinogen to $\alpha_{\mathrm{II}} \beta_{3}$ and platelet aggregation, it can potentiate the ability of platelet agonists to do so. Notably, each of the agonists that were tested (SFLLRN, U46619, and ionomycin) cause an increase in cytosolic $\mathrm{Ca}^{++}$, which does not occur with GST-EphB1. This suggests that the inability of isolated Eph/ephrin signaling to activate $\alpha_{\text {IIb }} \beta_{3}$ is due in part to the failure of such signaling to mobilize $\mathrm{Ca}^{++}$.

\section{Increased activation of Rap1}

Although the mechanisms underlying $\alpha_{\text {IIb }} \beta_{3}$ activation in platelets are not fully understood, recent studies suggest that the Ras-related protein, Rap1, is involved. ${ }^{15-20}$ Like other Ras family members, Rap1 is active in the GTP-bound state and inactive when bound to guanosine 5'-diphosphate (GDP). In theory, agonists can cause an increase in GTP-bound Rap1 either by turning on (or recruiting) a guanine nucleotide exchange factor (GEF) or by inhibiting a Rap1 GTPase-activating protein (GAP). We have shown previously that oligomerization of ephrinB1 by EphB1 in platelets activates Rap1 in the absence of an agonist. ${ }^{1}$ To see whether this response to ephrinB1 signaling enhances the ability of an agonist to activate
Rap1 and might, therefore, explain the observed enhancement of aggregation, platelets were incubated with the $\mathrm{TxA}_{2}$ analog, U46619, in the presence or absence of GST-EphB1. Rap1 activation was detected using a pull-down assay with a binding protein specific for the GTP-bound form of Rap1, which was then detected by immunoblotting with a Rap1 antibody. U46619 by itself caused Rap1 activation. Addition of GST-EphB1 caused a further increase in Rap1 activation (Figure 4A). GST-EphB1 also enhanced the ability of ionomycin to activate Rap1.

To understand how ephrinB1 activation might lead to Rap1 activation, platelets were preincubated with either apyrase, LY294002, or PP2 to, respectively, hydrolyze secreted ADP and inhibit PI3-kinases or Src family members. Afterward, the platelets were incubated with GST-EphB1, and Rap1 activation was measured (Figure 4B). Treating platelets with apyrase caused a small

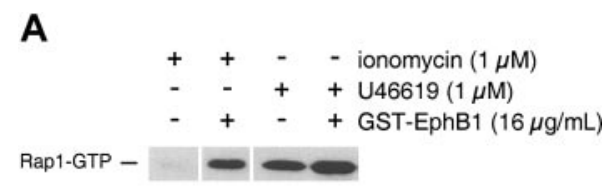

B
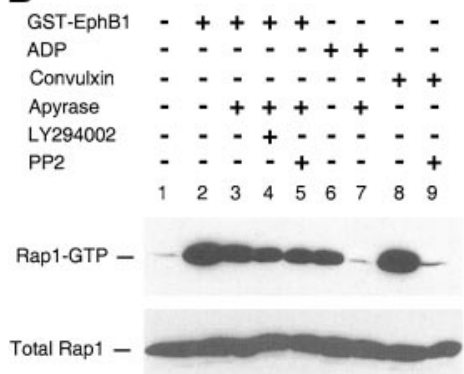

Figure 4. EphrinB1 signaling potentiates Rap1 activation. (A) Gel-filtered platelets were incubated with the agents indicated, then Rap1-GTP was isolated and analyzed as described in "Materials and methods." (B) Washed platelets (500 $\times$ $10^{9} / \mathrm{L}$ ) were preincubated for 15 minutes with apyrase $1 \mathrm{U} / \mathrm{mL}$, LY294002 $100 \mu \mathrm{M}$, PP2 $30 \mu \mathrm{M}$, or vehicle, then stimulated with agonist for 5 minutes. The results are from 1 of 2 experiments with identical results. 
decrease in GTP-bound Rap1 in response to GST-EphB1 (Figure 4B lanes 1-3) but eliminated Rap1 activation by ADP (Figure 4B lanes 6-7), suggesting that ephrinB1 is able to promote Rap1 activation by a mechanism that is largely independent of secreted ADP. The Rap1 activation that was observed in the presence of apyrase (ie, the Rap1 activation that is not secondary to ADP release) was minimally affected by inhibiting either PI3-kinase or Src family members (Figure 4B lanes 4-5). Notably, under the same conditions, inactivation of the Src family members in platelets with PP2 abolished Rap1 activation by convulxin (Figure 4B lanes 8-9) showing that GST-EphB1 and convulxin (which binds to glycoprotein VI [GP VI]) employ different mechanisms for Rap1 activation. Convulxin signals via the GP VI/Fc $\gamma$ complex, which requires phosphorylation of the Fc $\gamma$ chain cytoplasmic domain by a Src family member in order for events such as phospholipase $\mathrm{C} \gamma$ activation to occur. Potential mechanisms for Rap1 activation by ephrinB1 are discussed in "Mechanisms of ephrinB1 signaling."

\section{Mechanisms of ephrinB1 signaling}

Two mechanisms for protein/protein interactions and signaling have been identified for ephrin B family members: one is mediated by the PDZ target domain at the distal C-terminus of the ephrin, the other depends on the phosphorylation of tyrosine residues within the cytosolic domain of the ephrin by Src family members. ${ }^{5,6}$ In view of the fact that PP2 did not inhibit Rap1 activation by ephrinB1, we asked whether ephrinB1 can become phosphorylated in platelets. In Figure 5A-B, platelets were incubated with GSTEphB1, GST- $\Delta$ EphB1, or monomeric EphB1 exodomains (denoted His-EphB1 in Figure 5). Afterward, ephrinB1 was precipitated and blotted for phosphotyrosine. The results show that ephrinB1 is not phosphorylated in resting platelets but becomes phosphorylated when platelets are incubated with GST-EphB1. On the other hand, neither GST- $\Delta$ EphB1 nor the monomeric EphB1 exodomains cause ephrinB1 phosphorylation. The time course of phosphorylation in response to GST-EphB1 is similar to the time course for platelet adhesion to fibrinogen (compare Figures $1 \mathrm{~B}$ and 5B). Similarly, addition of GST-ephrinA4 to platelets caused phosphorylation of EphA4 (Figure 5C).

Although these data show that ephrinB1 can become phosphorylated in platelets, they do not establish that phosphorylation is required for ephrinB1-initiated responses and, in fact, this does not appear to be the case. In the experiments shown in Figure 6, ephrinB1 phosphorylation and platelet adhesion were measured in the presence of the Src inhibitor, PP2. PP2 (but not the inactive congener, PP3) abolished ephrinB1 phosphorylation in response to GST-EphB1. However, PP2 had no effect on platelet adhesion to fibrinogen (Figure 6B). An additional control showed that adhesion in response to convulxin was, as would be expected, abolished by PP2. As a final step, we measured the phosphotyrosine content of ephrinB1 immunoprecipitated from platelets that had been allowed to aggregate in response to PMA, ADP, SFLLRN, convulxin, U46619, or ionomycin. None of these agonists caused detectable ephrinB1 phosphorylation (Figure 6C). Therefore, we conclude that although ephrinB1 can become phosphorylated when directly stimulated in platelets, phosphorylation is not required for adhesion, nor does it occur at a detectable level during the Eph/ephrin interactions that accompany agonist-induced platelet aggregation.

If ephrinB 1 signaling in platelets does not require phosphorylation of the ephrin, what other mechanisms are involved? To address that question, GST-EphB1-induced adhesion was measured in the presence of apyrase, the protein kinase $\mathrm{C}$ inhibitor, bis-indolylmaleimide, and the PI3-kinase inhibitors, wortmannin and LY294002.
A

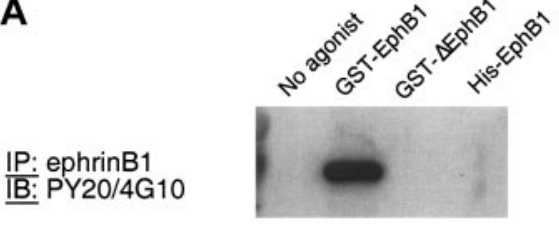

IB: ephrinB1

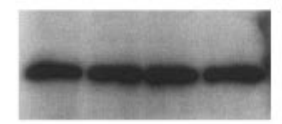

B

Incubation time (min)

$\begin{array}{lllll}0 & 15 & 30 & 45 & 60\end{array}$

IP: ephrinB1

IB: PY20/4G10

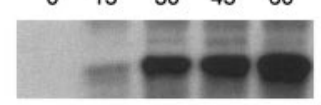

IB: ephrinB1

GST-EphB1

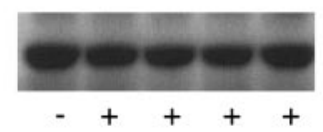

C

Incubation time $(\mathrm{min})$

$\begin{array}{llllll}0 & 5 & 15 & 30 & 45 & 60\end{array}$
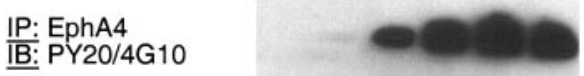

IB: EphA4

GST-ephrinA4

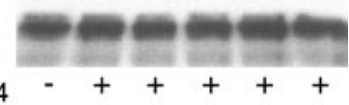

Figure 5. Phosphorylation of ephrinB1 and EphA4 in platelets. (A) Platelets were incubated with GST-EphB1 $(5 \mu \mathrm{g} / \mathrm{mL})$, GST- $\Delta$ EphB1 $(5 \mu \mathrm{g} / \mathrm{mL})$, or monomeric His-EphB1 $(10 \mu \mathrm{g} / \mathrm{mL})$ for 30 minutes and then lysed. EphrinB1 was immunoprecipitated (IP) and then immunoblotted (IB) with the antiphosphotyrosine antibodies PY20 and 4G10. Afterward, the blots were reprobed with anti-ephrinB1. The results shown are representative of 2 experiments. (B) Platelets were incubated with GST-EphB1 (5 $\mu \mathrm{g} / \mathrm{mL}$ ) for the times indicated. EphrinB1 was immunoprecipitated and then immunoblotted as indicated. (C) Platelets were incubated with GST-ephrinA4 for the times indicated and then lysed. EphA4 was immunoprecipitated and then immunoblotted as indicated. The results are representative of 3 experiments.

The results are shown in Figure 7. Apyrase blocked the effects of exogenous ADP but had no significant effect on adhesion in response to GST-EphB1. In contrast, inhibition of protein kinase $\mathrm{C}$ with bis-indolylmaleimide blocked adhesion. Adhesion was also inhibited by wortmannin and LY294002, although notably inhibition of PI3-kinase did not prevent Rap1 activation (Figure 4). Taken together, these results suggest that PI3-kinase plays a role in ephrinB1-dependent adhesion, but this role is either downstream of Rap1 activation or on a separate pathway.

\section{Discussion}

The initial stages of platelet activation in vivo are heavily dependent on signaling through $\mathrm{G}$ protein-coupled receptors or the GP VI complex, leading to the activation of phospholipase $\mathrm{C} \beta$ and $\gamma$ isoforms and, eventually, activation of $\alpha_{\mathrm{IIb}} \beta_{3}$. Although this is sufficient to initiate platelet aggregation, additional signaling events appear to have a role in the continued growth and stability of the hemostatic plug. These events are dependent upon or facilitated by platelet-platelet contacts that can only occur once platelet aggregation has begun. Outside-in signaling through integrins 
A

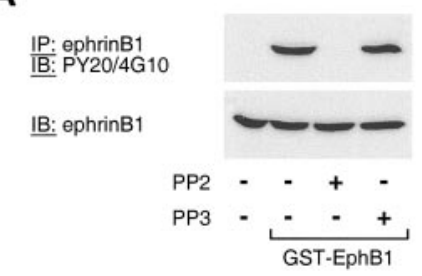

B

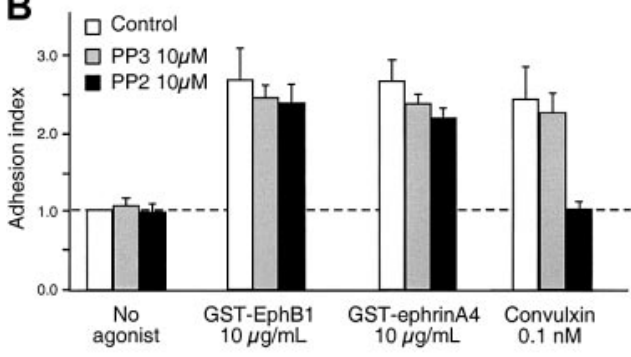

C

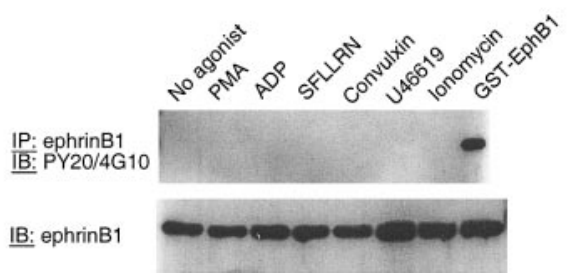

Figure 6. Phosphorylation of ephrinB1 during adhesion and aggregation. (A) Platelets were preincubated with $10 \mu \mathrm{M}$ PP2, $10 \mu \mathrm{M}$ PP3, or vehicle for 10 minutes at room temperature and then activated with GST-EphB1 $(3 \mu \mathrm{g} / \mathrm{mL})$ for 30 minutes. EphrinB1 was immunoprecipitated and then immunoblotted with the antiphosphotyrosine antibodies PY20 and $4 \mathrm{G} 10$ or with anti-ephrinB1. The results shown are representative of 2 experiments. (B) Platelets were preincubated for 15 minutes with either PP2 or PP3 and then stimulated for 20 minutes with GST-EphB1 or GST-ephrinA4 in fibrinogen-coated wells. The results shown are the mean \pm SEM for 4 experiments. (C) Platelets were incubated with an agonist for 5 minutes under conditions allowing aggregation to occur or with GST-EphB1 for 30 minutes as a control, after which ephrinB1 was immunoprecipitated and then immunoblotted with either PY20 and 4G10 or with anti-ephrinB1. Final concentrations: PMA 100 nM, ADP $20 \mu \mathrm{M}$, SFLLRN $50 \mu \mathrm{M}$, convulxin $1 \mu \mathrm{M}$, U46619 $5 \mu \mathrm{M}$, ionomycin $5 \mu \mathrm{M}$, and GST-EphB1 $5 \mu \mathrm{g} / \mathrm{mL}$. The results shown are representative of 3 experiments. The same results were obtained when the incubation with the agonists was extended to 30 minutes.

represents one example of contact-dependent signaling. Thus, platelets from mice in which outside-in signaling through $\alpha_{\text {IIb }} \beta_{3}$ has been impaired by mutating Y747 and Y759 in the cytoplasmic domain of $\beta_{3}$ have a phenotype that includes impaired aggregation and defective clot retraction..$^{21,22}$

We have proposed previously that Eph/ephrin interactions provide an additional source of contact-dependent signaling during human platelet plug formation. In support of this hypothesis, we have shown elsewhere that forced clustering of EphA4 and ephrinB1 causes platelets to adhere and spread on immobilized fibrinogen, and that blockade of Eph/ephrin interactions inhibits platelet aggregation. ${ }^{1,11,12}$ In this study, we investigated how Eph-ephrin signaling might contribute to platelet adhesion and aggregation. We were particularly interested in understanding how ephrinB1 might contribute to platelet activation since ephrinB1, like other ephrin B family members, lacks intrinsic kinase activity and can serve solely as a means to oligomerize (and activate) Eph kinases or can generate signals itself. The results show that at least 2 separate mechanisms appear to be at work.

Stated succinctly, our results show the following: (1) Isolated Eph-ephrin signaling is sufficient to initiate platelet adhesion to fibrinogen but not the binding of soluble fibrinogen or aggregation. (2) Platelet adhesion to fibrinogen initiated by ephrin signaling is blocked by RGDS and A2A9 and is therefore mediated by $\alpha_{\text {IIb }} \beta_{3}$. (3) Although insufficient to cause platelet aggregation, Eph/ephrin signals can enhance aggregation induced by agonists or by a $\mathrm{Ca}^{++}$ ionophore and potentiate Rap1 activation. (4) Eph/ephrinmediated adhesion occurs slowly in comparison to other agonists (10-30 minutes), but the ability of Eph/ephrin interactions to potentiate aggregation is evident immediately. (5) Ephrin-mediated adhesion is dependent on PI3-kinase and protein kinase $\mathrm{C}$ but activation of Rap1 is not. (6) Both adhesion and Rap1 activation by ephrinB1 require clustering of the ephrin, but neither requires tyrosine phosphorylation of ephrinB1 nor the involvement of Src family kinases.

The involvement of $\alpha_{\mathrm{IIb}} \beta_{3}$ is not unexpected but revealing, nonetheless, in light of other observations. Whatever the activation state of $\alpha_{\mathrm{IIb}} \beta_{3}$ required for the integrin to bind to immobilized as opposed to soluble fibrinogen, it is now clear that isolated Eph kinase and ephrin signaling can achieve the former but not the latter. The observation that signaling through Eph kinases can regulate the adhesive function of integrins is consistent with previous studies. ${ }^{23-26}$ However, most of those studies were performed using cells that are normally adherent, unlike platelets, and both increases and decreases in integrin function were observed. For example, activation of EphB1 causes endothelial cells to attach via $\alpha_{\mathrm{v}} \beta_{3}^{23}$ and P19 cells to attach to fibrinogen. ${ }^{25}$ On the other hand, activation of EphB2 on NIH-3T3 or HEK-293T cells inhibits adhesion, ${ }^{24}$ and activation of EphA2 in PC-3 cells inhibits both adhesion and spreading. ${ }^{26}$ Whether Eph/ephrin signaling causes an increase or decrease in integrin function presumably depends on the repertoire of effector molecules expressed in a given cell type. On platelets, an increase in attachment due to Eph/ephrin signaling appears to be the rule.

Although signaling through ephrinB1 is insufficient to cause soluble fibrinogen binding or platelet aggregation, it is clearly able to potentiate platelet responses to agonists. If Eph/ephrin interactions are to extend and stabilize platelet aggregates after they begin to form, as we hypothesize, then we might expect that signaling by Eph kinases and ephrins would be especially important in platelets that have also been exposed to soluble agonists. Thus, our observation that ephrin signaling enhances aggregation only in the presence of other agonists is a finding that supports this hypothesis.

If signaling through ephrinB1 promotes integrin engagement and supports aggregation in platelets, how does it do so? One leading possibility is that the potentiation of aggregation is linked to the activation of Rap1. Several prior observations have suggested that Rap1 activation promotes integrin activation in platelets. For example, Bertoni et $\mathrm{a}^{17}$ have shown that overexpression of an inactive Rap1 mutant inhibits agonist-induced $\alpha_{\mathrm{IIb}} \beta_{3}$ activation

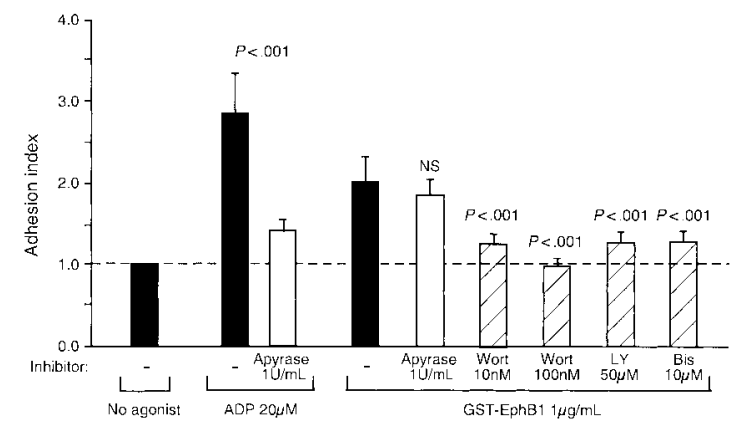

Figure 7. Inhibition of GST-ephrinB1-induced platelet adhesion. Platelets were preincubated for 15 minutes with each inhibitor and then stimulated for 20 minutes with GST-EphB1 or ADP. The results are the mean \pm SEM for 6 experiments. 
in megakaryocytes. They also found that expression of constitutively active Rap1 was not sufficient by itself to activate $\alpha_{\text {IIb }} \beta_{3}$ but potentiated activation of the integrin by an agonist, as does signaling through ephrinB1. Together with our data showing that ephrin B1 signaling activates Rap1 and potentiates the ability of other platelet agonists to do so, this suggests that ephrin signaling potentiates aggregation by enhancing activation of Rap1.

If isolated ephrinB1 signaling can cause Rap1 activation, why does it not also cause platelet aggregation? The studies in megakaryocytes cited above suggest that activated Rap 1 by itself is incapable of activating $\alpha_{\text {IIb }} \beta_{3}$. However, clustering of ephrinB1 in platelets enhances aggregation and activation of Rap1 in response to $\mathrm{Ca}^{++}$ionophore. Because ephrinB1 signaling by itself does not cause an increase in the cytosolic $\mathrm{Ca}^{++}$concentration in platelets, ${ }^{1}$ it appears that the combination of ephrin signaling plus an increase in cytosolic $\mathrm{Ca}^{++}$provides everything needed for platelets to bind soluble fibrinogen and aggregate.

Finally, the results of the present studies provide additional information about the molecular basis for signaling by ephrinB1 in platelets. Unlike the receptor kinases EphA4 and EphB1, ephrinB1 lacks a kinase domain. However, ephrins also become activated when they are bound and clustered by their surface ligands. Clustered ephrins then serve as the nidus for signaling complexes. Two distinct modes of signaling downstream of ephrin B family members have been identified: one is dependent on tyrosine phosphorylation of the cytosolic domain of the ephrin by a Src family member, followed by the binding of protein(s) with Src homology 2 (SH2) or phosphotyrosine binding protein (PTB) domains $^{5,6}$; the other is dependent on the binding of cytosolic proteins with PDZ domains. ${ }^{27-30}$ The present studies show quite clearly that ephrinB1 phosphorylation is not required in platelets: complete elimination of phosphorylation had no effect on either adhesion or Rap1 activation. This novel finding in platelets extends a very recent report of phosphorylation-independent activation of c-Jun N-terminal kinase (JNK) by ephrinB1. ${ }^{31}$

The alternative to phosphotyrosine-based interactions is the PDZ target domain in ephrinB1. Guanine nucleotide exchange factors (GEFs) for Ras family members interact with B ephrins by this mechanism. Whether an appropriate PDZ-containing GEF exists in platelets and performs this function for Rap1 remains to be established. However, a direct link of this sort would be expected to be phosphorylation independent and thus not inhibited by PP2, as we have shown for ephrinB1-induced Rap1 activation. Such a link

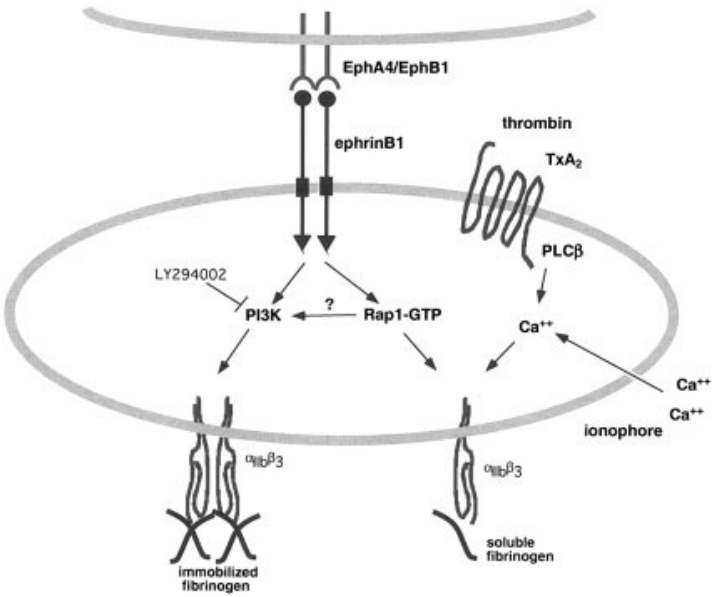

Figure 8. Eph/ephrin signaling in platelets promotes integrin engagement. EphrinB1 on the surface of platelet can serve as both a ligand for Eph kinases on adjacent platelets and as the focus for a signaling complex that promotes Rap1 activation and integrin engagement in response to agonists.

would also be expected to be independent of PI3-kinase activity, which is also the case with ephrinB1-induced Rap1 activation. The fact that PI3-kinase inhibitors reduce adhesion, but not Rap1 activation, would suggest that PI3-kinases support adhesion in a pathway that is either downstream of Rap1 activation or independent of Rap1 activation (Figure 8).

In conclusion, the present studies show that activation of EphA4 and ephrinB1 on the platelet surface can support the binding of $\alpha_{\text {IIb }} \beta_{3}$ to immobilized fibrinogen and promotes aggregation in response to biologically relevant platelet agonists. A sustained activation of the integrin in the context of a fibrin- and fibrinogenembedded hemostatic plug would be expected to help to stabilize the plug. Taken together, these results provide a mechanism by which Eph/ephrin interactions can support the growth and stability of the hemostatic plug and point to the direction in which the necessary downstream effectors in platelets can be found.

\section{Acknowledgments}

We thank Gaston Vilaire, Joel Bennett, Hong Chen, Mark Kahn, Peter O'Brien, and Jing Yang for many helpful discussions.

\section{References}

1. Prevost N, Woulfe D, Tanaka T, Brass LF. Interactions between Eph kinases and ephrins provide a novel mechanism to support platelet aggregation once cell-to-cell contact has occured. Proc Nat Acad Sci U S A. 2002;99:9219-9224.

2. Wilkinson DG. Eph receptors and ephrins: regulators of guidance and assembly. Int Rev Cytol. 2000;196:177-244.

3. Adams RH, Klein R. Eph receptors and ephrin ligands: essential mediators of vascular development. Trends Cardiovasc Med. 2000;10:183-188.

4. Cheng N, Brantley DM, Chen J. The ephrins and Eph receptors in angiogenesis. Cytokine Growth Factor Rev. 2002;13:75-85

5. Schmucker D, Zipursky SL. Signaling downstream of Eph receptors and ephrin ligands. Cell. 2001;105:701-704

6. Kullander K, Klein R. Mechanisms and function of Eph and ephrin signaling. Nat Rev Mol Cell Biol. 2002;3:475-486.

7. Gale NW, Holland SJ, Valenzuela DM, et al. Eph receptors and ligands comprise two major specificity subclasses and are reciprocally compartmentalized during embryogenesis. Neuron. 1996; 17:9-19.

8. Holland SJ, Gale NW, Mbamalu G, Vancopoulos GD, Henkemeyer M, Pawson T. Bidirectional signaling through the the EPH-family receptor Nuk and its transmembrane ligands. Nature. 1996; 383:722-725.

9. Mellitzer $G, X u Q$, Wilkinson DG. Control of cell behavior by signalling through Eph receptors and ephrins. Curr Opin Neurobiol. 2000;10:400-408.

10. Prevost N, Woulfe D, Tognolini M, Brass LF. Contact dependent signaling during the late events of platelet activation. J Thrombos Heamostas. 2003; 1:1613-1627.

11. Woulfe D, Prevost N, Jiang H, Tognolini M, Fortna $\mathrm{R}$, Brass LF. Eph receptor-ephrin interactions contribute to the tyrosine phosphorylation of the cytoplasmic domain of the $\beta$ subunit of $\alpha_{\| b} \beta_{3}$ during platelet aggregation [abstract]. Blood. 2002; 100:477a.
12. Prevost N, Fortna R, Tognolini M, Woulfe D, Wu J, Brass LF. Contact-dependent signaling by Eph kinases and ephrins promotes the late phases of platelet activation, including clot retraction [abstract]. Blood. 2002;100:477a.

13. Bellavite P, Andrioli G, Guzzo P, et al. A colorimetric method for the measurement of platelet adhesion in microtiter plates. Anal Biochem. 1994;216: 444-450.

14. Himanen JP, Henkemeyer M, Nikolov DB. Crystal structure of the ligand binding domain of the receptor tyrosine kinase EphB2. Nature. 1998;396: 486-491.

15. Reedquist KA, Ross E, Koop EA, et al. The small GTPase, Rap1, mediates CD31-induced integrin adhesion. J Cell Biol. 2000;148:1151-1158.

16. Katagiri K, Hattori M, Minato N, Irie S, Takatsu K, Kinashi T. Rap1 is a potent activation signal for leukocyte function-associated antigen 1 distinct from protein kinase $\mathrm{C}$ and phosphatidylinositol3-OH kinase. Mol Cell Biol 2000;20:1956-1969.

17. Bertoni A, Tadokoro S, Eto K, et al. Relationships 
between Rap1b, affinity modulation of integrin $\alpha_{\| 1 b} \beta_{3}$, and the actin cytoskeleton. J Biol Chem. 2002;277:25715-25721.

18. Eto K, Murphy R, Kerrigan SW, et al. Megakaryocytes derived from embryonic stem cells implicate CalDAG-GEFI in integrin signaling. Proc Natl Acad Sci U S A. 2002:99:12819-12824.

19. De Bruyn KMT, Zwartkruis FTJ, De Rooij J, Akkerman J-WN, Bos JL. The small GTPase Rap1 is activated by turbulence and involved in integrin $\alpha_{\| l b} \beta_{3}$-mediated cell adhesion in human megakaryocytes. J Biol Chem. 2003;278:2241222417.

20. Sebzda E, Bracke M, Tugal T, Hogg N, Cantrell DA. Rap1A positively regulates $T$ cells via integrin activation rather than inhibiting lymphocyte signaling. Nat Immunol. 2002;3:251-258.

21. Law DA, DeGuzman FR, Heiser P, Ministri-Madrid K, Killeen N, Phillips DR. Integrin cytoplasmic tyrosine motif is required for outside-in $\alpha_{\| 1 \mathrm{~b}} \beta_{3}$ signalling and platelet function. Nature. 1999;401: 808-811.
22. Phillips DR, Nannizzi-Alamio L, Prasad KSS Beta3 tyrosine phosphorylation in alphallbbeta3 (platelet membrane GP IIb-IIla) outside-in integrin signaling. Thromb Haemost. 2001;86:246-258.

23. Huynh-Do U, Stein E, Lane AA, Liu H, Cerretti DP, Daniel TO. Surface densities of ephrin-B1 determine EphB1-coupled activation if cell attachment through alphavbeta3 and alpha5beta1 integrins. EMBO J. 1999;18:2165-2173.

24. Zou JX, Wang B, Kalo MS, Zisch AH, Pasquale EB, Ruoslahti E. An Eph receptor regulates integrin activity through R-Ras. Proc Natl Acad Sci U S A. 1999;96:13813-13818.

25. Becker E, Huynh-Do U, Holland S, Dawson T, Daniel TO, Skolnik EY. Nck-interacting Ste20 kinase couples Eph receptors to c-Jun N-terminal kinase and integrin activation. Mol Cell Biol. 2000;20:1537-1545

26. Miao H, Burnett E, Kinch M, Simon E, Wang B. Activation of EphA2 kinase suppresses integrin function and causes FAK dephosphorylation. Nat Cell Biol. 2000;2:62-69.
27. Torres R, Firestein BL, Dong HL, et al. PDZ proteins bind, cluster, and synaptically colocalize with Eph receptors and their ephrin ligands. Neuron. 1998;21:1453-1463.

28. Lin D, Gish GD, Songyang Z, Pawson T. The carboxyl terminus of $B$ class ephrins constitutes a PDZ binding motif. J Biol Chem. 1999;274:37263733.

29. Lu Q, Sun EE, Klein RS, Flanagan JG. Ephrin-B reverse signaling is mediated by a novel PDZRGS protein and selectively inhibits G proteincoupled chemoattraction. Cell. 2001;105:69-79.

30. Bruckner K, Pablo Labrador J, Scheiffele P, et al EphrinB ligands recruit GRIP family PDZ adaptor proteins into raft membrane microdomains. Neuron. 1999;22:511-524.

31. Xu Z, Kwok-On L, Zhou H-M, Lin S-C, Ip NY. Ephrin-B1 reverse signaling activates JNK through a novel mechanism that is independent of tyrosine phosphorylation. J Biol Chem. 2003;278:2476724775 . 